Virtual Mentor. September 2003, Volume 5, Number 9.

doi: 10.1001/virtualmentor.2003.5.9.ccas1-0309

Clinical Cases

\title{
An Impaired Physician's Physician
}

\section{Physicians must show appropriate concern, compassion, and sensitivity when treating other physicians as patients, especially when faced with the possibility of a debilitating illness.}

Commentary by Peter Mansky, MD, Claire Wang, MD, and Leonard Morse, MD

Dr. George Redden is an obstetrician/gynecologist in a small town. He has been in practice for 26 years, the last 20 of them in his current practice. Most of his patients are healthy young women with low-risk pregnancies. He often sees children he delivered at his grandchildren's school performances. He likes to stop and chat with the women he saw through pregnancy and find out how they and their children are doing. Dr. Redden has been thinking of retiring in the next 7 or 8 years and has been talking to his wife recently about his desire to continue practicing medicine part-time during his retirement.

About 2 years ago Dr. Redden visited his own long-time physician, Dr. Charles Turner, for a regular check-up. Dr. Turner checked Dr. Redden's blood pressure, his cholesterol, and prostate.

"George, you seem to be doing well. All systems are go," Dr. Turner explained. "I did notice one thing that I would like to check into further. I have been seeing a slight tremor in your left hand."

Dr. Redden crossed his right hand over his left and shrugged. In the past few months his hand had begun to tremble uncontrollably when he was resting it on an armchair or just sitting with his hands in his lap. This tremor was embarrassing and becoming more and more difficult to hide. He had found that he if moved his hand immediately or tried to pick up an object sometimes the tremor would stop. But recently his wife had commented on it and he had simply brushed it off as a muscle spasm.

"It seems to be a resting tremor, George. Maybe we should do some further tests," Dr. Turner suggested.

"I think it's just a tremor. You know, we're getting old, Charlie," Dr. Redden explained. "It's not a problem, I'm righthanded anyway, and it doesn't bother me."

"If it gets any worse I want you to come back to me so we can run some tests."

Dr. Redden did not see Dr. Turner again for another 8 months when he came in with a case of strep throat that his granddaughter had brought home from preschool. Dr. Turner swabbed Dr. Redden's throat, and then left to give the sample to the lab to run a culture.

He returned to the exam room and sat down to write a prescription for Dr. Redden.

"George, how is that hand of yours? It seems to be getting worse," Dr. Turner commented as he noticed Dr. Redden's hand sitting in his lap shaking. "I noticed that you seemed a little unsteady, are you having any problems walking?"

"No, I'm fine. Maybe just a little tired today. You know my throat has really been bothering me." 
"What about trouble getting out of chairs, or out of the car?"

"No, no problems."

"What about problems with writing or typing?" Dr. Turner asked as he glanced down at the form that Dr. Redden had filled out in the waiting room. The print was incredibly small and difficult to read.

"Charlie, I'm fine. Are you going to give me that antibiotic or not?" Dr. Redden answered tersely.

"George, I think there is the possibility you are not fine. You seem to be progressively losing motor control. You need to see a neurologist. And I think you need to consider the fact that you may not be able to continue delivering babies."

Dr. Redden took the script Dr. Turner offered him, and turned to his friend and colleague, "Dr. Turner, delivering babies is my life, if I have to give that up what will I have to live for? I'll be at my office caring for my patients until the day I can't get out of bed."

\section{Commentary 1}

by Peter Mansky, MD

Dr. Redden is a physician who is dedicated to his practice and appears to attend to his own health needs as well. He has a primary physician and sees him on a routine basis. He has been doing so for years. Physicians in general start out with better health than the general population but they do not take as good care of themselves. Many physicians in good health often do not have primary physicians to whom they go to on a regular basis. These physicians will settle for curbside diagnoses or consultations and then treat themselves [1-4]. It is noteworthy that Dr. Redden did not treat himself for a sore throat but sought treatment through his primary care physician. Many physicians would have just written a prescription for themselves. It is not illegal or medical misconduct to write a prescription for oneself or to diagnose an illness in oneself, although the AMA's Code of Ethics advises against doing so. It's just doesn't provide good medical care.

The one exception in Dr. Redden's self care is his failure to address his movement disorder and to obtain an expert diagnoses. Instead of showing concern, he minimizes the significance of his resting tremor. This is most likely due to his concerns that he might have Parkinson's disease and represents a denial that is not uncommon especially in the face of a disease that could be disabling.

Dr. Turner showed appropriate concern for his patient and fellow physician who exhibited an abnormal tremor, most likely parkinsonian in nature. Dr. Turner's concern is based on his skills as a clinician and his ethical responsibilities to a fellow physician. There is no doubt that Dr. Turner's concern and his expression of this concern for his patient and colleague is to be applauded. I am not an ethicist, but it appears to me that Dr. Turner's actions were highly ethical and in accordance with the Hippocratic Oath and Maimonides Physician's Prayer. Both of these documents form a strong basis for our ethical standards as physicians and have been included in the graduation exercises of medical schools in this country.

The ethical standards in the Hippocratic Oath specify giving excellent care and support to our fellow physicians as well as to our patients: "I will keep this Oath and this stipulation to reckon him who taught me this Art equally dear to me as my parents" [5]. The Maimonides Physician's Prayer asks that the physician only see the human being in the sufferer and "ever be ready to cheerfully help and support rich and poor, good and bad, enemy as well as friend ...Do not allow thirst for profit, ambition for renown and admiration, to interfere with my profession." The prayer also calls for support of the physician "in this great task so that it may benefit mankind," and for illumination of the physician's "mind that it recognize what presents itself and that it may comprehend what is absent or hidden." The essence of this prayer is an entreaty for physicians to be able to give unbiased care to patients based only on their clinical skills, which include both the professional knowledge of diseases and an understanding of the human factors effecting patients. This is so very important when we treat our fellow physicians. Our admiration for their ability and skills, our identification with the struggles they are facing accompanied by their anguish and pain, and our relationship to them as colleagues in 
the community need to be tempered by our clinical skills.

Reflecting upon caring for fellow physicians allows one to realize that helping a colleague has very high value in the mission of the medical profession to diagnose, treat, and promote healing in our patients. Help and care that is given to a fellow physician can be multiplied by the positive effect of the professional activities of that physician in his or her own practice. Thus, helping a colleague helps many patients to benefit from the care of that physician.

In treating other physicians, one must be careful to do so in a way that is compassionate but does not lead to the immediate rejection of the clinical recommendations. This may require skills that we have not routinely used as practicing clinicians. Dr. Turner's first 2 statements "George, I think there is the possibility you are not fine. You seem to be progressively losing motor control. You need to see a neurologist." are stated in an ethical, effective, and caring manner. It takes more than a modicum of courage to confront our fellow clinicians. The last statement- that Dr. Redden should consider giving up his obstetrical practice-leads immediately to resistance. Dr. Turner needs to first obtain an expert evaluation before he can counsel a change in the work situation. If the treating physician immediately brings up the practice issue, this may lead to resistance and even to the issue being dismissed and ignored.

State Physician Health Programs (PHP) may provide aid and assistance to physicians such as Dr. Turner in helping their colleagues especially when it relates to factors that affect a colleague's practice. The programs can help physicians deal with illness that may have a potential for disability and possibly impairment at the work site. State PHP's exist in 48 states and the District of Columbia. Most have affiliation with the state medical society. About 60 percent regularly help physicians deal with a physical illness. Those that don't regularly provide this type of help may provide advice and guidance for physicians such as Dr. Turner who want to be effective in counseling their fellow physicians concerning practice issues. When one physician confronts another about the effects of illness on the practice of medicine, it is easy for the confronted physician to disregard the advice and even to degrade the clinical skills of the physician giving the advice. When presented by several physicians or a group of clinicians who have both awareness of the illness and the impact of illness on the practice of medicine, the confronted physician is more likely to heed the advice.

\section{References}

1. Mansky PA. The impaired physician. In: Galanter M, Kleber HD, eds. Textbook of Substance Abuse Treatment. 3rd ed. Washington DC: The American Psychiatric Press; in press.

2. Gross CP, Mead LA, Ford, DE, Klag MJ. Physician, heal thyself? Regular source of care and use of preventive health services among physicians. Arch Intern Med. 2000;160:3209-3214.

View Article PubMed Google Scholar

3. Frank E, Brogan DJ, Mokdad AH, Simoes EJ, Kahn HS. Health-related behaviors of women physicians vs other women in the United States. Arch Intern Med. 1998;158:342-8.

View Article PubMed Google Scholar

4. Frank E. Research isues for physician health programs in prevention and special populations. Presented at: Physician Health Research Conference; September 15-17,1996; Estes Park, Colorado.

5. Massachusetts Institute of Technology Internet Classics Web site. Hippocrates. The oath. Adams F, trans-ed. Available at: http://classics.mit.edu//Hippocrates/hippooath.html. Accessed August 25, 2003.

Peter Mansky, MD, has been the medical director for the New York Committee For Physicians' Health of the Medical Society of the State of New York (the NY Physicians' Health Program) for over 11 years. He is a professor of psychiatry and pharmacology at Albany Medical College and has a small private practice. He is also a member of the board of directors of the American Society of Addiction Medicine and treasurer of the Federation of State Physician Health Programs.

\section{Commentary 2}


Several medical organizations address physician impairment in their codes of ethics. The American College of Emergency Physicians states that "whenever a colleague or consulting physician is believed to be incompetent or impaired by drugs, alcohol, or psychiatric or medical conditions, there is a duty to report the impaired physician to the chief of service, the chief of medical staff, and appropriate committees or regulatory agencies" [1]. The American College of Physicians concurs, stating that "there is a clear ethical responsibility to report a physician who seems to be impaired to an appropriate authority" [2]. The American Medical Association also holds the opinion that "physicians have an ethical obligation to report impaired, incompetent, and unethical colleagues" [3].

In Dr. Turner's situation, he suspects that his patient, Dr. Redden, has Parkinson's disease and may someday be unable to deliver competent care to his patients. Before Dr. Redden's condition progresses to the extent that he is clearly unfit to practice, what can Dr. Turner do to prevent the unpleasant prospect of reporting his colleague and friend?

\section{"Ignoring it won't make it go away"}

As patients, physicians may deny or minimize their own symptoms for fear of what the symptoms mean, a reluctance to interact with the health care system as a patient, and worries over how an illness will affect their practice [4]. Unfortunately, such tendencies may hinder timely diagnosis and treatment and intensify emotional hardship.

If, as suspected, Dr. Redden has Parkinson's disease, the chronic progressive course of the disease will ultimately interfere with his ability to provide safe and effective care. This is true regardless of whether Dr. Redden chooses to accept or deny his condition. However, neurological evaluation and treatment may slow the course of disease progression and alleviate symptoms, enabling him to engage in meaningful activities for as long as possible.

Knowing how important it is for Dr. Redden to continue caring for his patients, Dr. Turner should acknowledge this immediately. He can also use this as an argument to pursue evaluation and treatment. For example, Dr. Turner can say, "I know how important it is for you to continue delivering babies, George. That's why I think it's best for you to see a neurologist. A neurologist can evaluate your condition and let you know where you stand. She may be able to prescribe treatment to control your tremor or slow the progression of your symptoms. Ignoring your condition won't make it go away, but it could make things harder for you in the long run."

The goal is not only for Dr. Redden to receive evaluation, treatment, and follow-up, but also for him to learn to accept his condition. Once Dr. Redden is willing to accept his condition, he can begin to plan for eventual changes in his lifestyle and practice.

\section{"It's better to take control of a situation than to let it take control of you"}

Early planning can help Dr. Redden equip himself emotionally and practically for future changes. In particular, when his motor and cognitive symptoms progress to the extent that he is unable to deliver babies competently, it will be time for him to retire from this aspect of his profession.

Dr. Turner can introduce this issue by asking, "What is it about delivering babies that makes it important to you, George?" Based on Dr. Redden's answers, Dr. Turner can help him explore alternatives that will still provide personal fulfillment. For example, if he enjoys interacting with his patients, can he delegate specific physical tasks to a partner? When he retires from practice altogether, can he interact with former patients and their children by engaging in volunteer work? If he values his identity as a healer, can he contribute through research or teaching? Would he like to preserve the memories of his years in practice by recording them in a journal?

Dr. Turner should help Dr. Redden understand that he has the option to make proactive decisions about his future rather than having changes imposed on him. Dr. Redden can take control of his situation by acknowledging that certain changes are inevitable (eg, "I will someday need to retire from clinical practice), predetermining when to make changes (eg, "I will retire from clinical practice when my neurologist advises me to"), and finding solutions to 
maintain his quality of life (eg, "When I retire, I will continue to contribute to my community through volunteer work.")

\section{"We will keep our patients from harm"}

In the best case scenario, Dr. Redden will agree to retire from practice when he becomes incapable of providing safe and effective care. However, in the event that he resists, Dr. Turner should counsel Dr. Redden, asking him to consider the safety of his patients and pointing out benefits to retirement. For example, Dr. Turner can explain that by planning his retirement, Dr. Redden will have the opportunity to say goodbye to his patients while ensuring that they have continuity of care. Also, he can avoid potential calamities, such as harming a patient, losing patients, or having his medical license revoked.

If all else fails, Dr. Turner should report Dr. Redden to an appropriate regulatory group, such as an institutional committee or a state medical licensing board [1-3]. Such regulatory groups are obligated to protect health care consumers and will consider the well-being of the consumer and the physician in determining a course of action. Because Dr. Turner will have reported Dr. Redden only as a last resort, he should feel confident that he has acted in the best interest of his patient and his profession.

\section{References}

1. American College of Emergency Physicians. Code of ethics for emergency physicians. Ann Emerg Med. 1997;30:365-372.

PubMed

2. American College of Physicians. Ethics manual. 4th ed. Ann Intern Med. 1998;128;576-594.

3. Opinion 9.031 Reporting Impaired, Incompetent, or Unethical Colleagues. American Medical Association. Code of Medical Ethics 2008-2009 Edition. Chicago, IL: American Medical Association; 2008:300-302.Google $\underline{\text { Scholar }}$

4. Goldman LS. When physicians become ill. In: Goldman LS, Myers M, Dickstein LJ (eds). The Handbook of Physician Health. Chicago, IL: American Medical Association; 2000:193-204.Google Scholar

Claire Wang, MD, is a scientist in the American Medical Association's Unit on Medicine and Public Health.

\section{Commentary 3}

by Leonard J. Morse, MD

Dr. Redden, as is often the case, is expressing denial concerning his health. He undoubtedly has served his community as an obstetrician-gynecologist for 26 years with distinction. He plans to continue to practice minimizing an involuntary tremor of his left hand because it is not interfering with his skills and dexterity. The obvious concern is that Dr. Redden's involuntary tremor is a manifestation of a degenerative neurologic disease that might necessitate the modifying of his medical practice. His physician, Dr. Turner, should have insisted on a neurology consultation when the tremor was first recognized. If Dr. Redden refuses the consultation, Dr. Turner should have asked the patient's permission to review his findings and recommendations with Dr. Redden's wife and family. With family encouragement Dr. Redden may have been more cooperative. I believe Dr. Turner initially should have been more persuasive in directing appropriate diagnostic and consultative care.

Physicians do not work unobserved and all "physicians have an ethical obligation to report impaired, incompetent, and unethical colleagues in accordance with the legal requirements of each state" [1]. The AMA's Code of Medical Ethics Opinion 9.031 is based on Principle II of the AMA's 9 Principles of Medical Ethics, which states that "a physician shall uphold the standards of professionalism, be honest in all professional interactions, and strive to report physicians deficient in character or competence, or engaging in fraud or deception, to appropriate entities" [2]. 
Dr. Redden, unfortunately, has early signs of physical impairment. He deserves a comprehensive neurologic medical evaluation to determine the cause of his tremor and to establish whether he has an impairment that presents a risk to his patients. Since he practices in a hospital, if the test results are positive the chief of obstetrics and gynecology should be informed. Following thorough neurologic evaluation and treatment, a decision concerning Dr. Redden's ability to safely resume his practice will be made. Perhaps, with treatment Dr. Redden's tremor will be significantly subdued and he will be able to return to work. If not, other options can be considered that will maximize Dr. Redden's interests, skills, and ability.

Dr. Redden's family deserves reassurance, and most importantly, so do his patients. It has been my experiences that when doctors, as patients, initially are in denial, extreme gratitude often follows clarification of the issues.

\section{References}

1. Opinion 9.031 Reporting Impaired, Incompetent, or Unethical Colleagues. American Medical Association. Code of Medical Ethics 2008-2009 Edition. Chicago, IL: American Medical Association; 2008:300-302. Google Scholar

2. Americian Medical Association. Principle II of medical ethics. Code of Medical Ethics and Current Opinions, 2002-2003 edition. Chicago: American Medical Association; xii.

Leonard Morse, MD, is currently the commissioner of public health in Worcester, MA and a professor of clinical medicine, family medicine, and community health at the University of Massachusetts Medical School. He is a past chair of the AMA's Council on Ethical and Judicial Affairs.

The people and events in this case are fictional. Resemblance to real events or to names of people, living or dead, is entirely coincidental. The viewpoints expressed on this site are those of the authors and do not necessarily reflect the views and policies of the AMA.

(C) 2003 American Medical Association. All Rights Reserved. 